\title{
Hybrid Virtual- and Field Work-based Service Learning with Green Information Technology and Systems Projects
}

\author{
K. Branker \\ Masters Candidate, Department of Mechanical and Materials Engineering \\ Queen's University \\ Kingston, ON K7L3N6 \\ brankerk@me.queensu.ca \\ J. Corbett \\ PhD Candidate, Queen's School of Business \\ Queen's University \\ Kingston, ON K7L3N6 \\ jcorbett@business.queensu.ca \\ J. Webster \\ Professor, Queen's School of Business \\ Queen's University \\ Kingston, ON K7L3N6 \\ jwebster@business.queensu.ca \\ J. M. Pearce \\ Professor, Department of Mechanical and Materials Engineering \\ Queen's University \\ Kingston, ON K7L3N6 \\ pearce@me.queensu.ca
}

\begin{abstract}
Traditional engineering service learning (SL) projects can be classified as: 1) collaborations with a community group or non-profit organization to provide specific engineering around a community need, or 2) an internship-like experience with industry to address work requested by a client. The limitation of both traditional SL approaches is that they do not prepare students to implement unprescribed projects (projects that are not commissioned). In contrast, in this work, students chose both the project and the partner for a self-directed engineering SL experience. This paper presents the findings of this novel pedagogical exercise in which students acted as change agents for industry by implementing unsolicited energy conservation measures (ECMs) focused on green information technology and systems (IT/S), in order to improve organizations' environmental and economic performance. The hybrid SL projects had both 'virtual' and 'real' (field-work) SL components. For the virtual component, student teams developed and published on-line, open-source ECM calculators. For the field-work component, the teams self-selected industry clients and performed IT/S energy audits. Applicable ECMs were then selected and tailored, forming the basis of recommendations to the organizations. Results demonstrate the effectiveness of such hybrid engineering SL projects in terms of improving student motivation, learning, and quality of work.
\end{abstract}

Index Terms - Energy Conservation, Green IT/S, Virtual Service Learning, Sustainability 


\section{INTRODUCTION}

Service learning (SL) is a teaching methodology that entails experiential education through the combination of academic instruction with community service, focusing on civic responsibility and critical, reflective thinking. It is well-established that, through linking community service and academic work, each is strengthened ${ }^{\mathrm{ii}}$. Thus, "experience-based education creates a powerful learning environment, which results in new educational outcomes" "iii and such education can be facilitated by SL in engineering courses. There is a vast amount of literature evidencing the positive outcomes of SL for students, faculty, educational institutions, and community partners $^{\mathrm{iv}, \mathrm{v}, \mathrm{vi}}$. For example, service learning has beneficial impacts on students' academic learning, course objective development, moral development, and ability to apply academic knowledge to "real world" applications ${ }^{\text {vii,viii }}$. Students are, therefore, the largest benefactors as they gain increased motivation, better academic outcomes, and real world experiences $^{\mathrm{ix}, \mathrm{x}, \mathrm{xi}, \mathrm{xii}, \mathrm{xiii}, \mathrm{xiv}, \mathrm{xv}, \mathrm{xvi}}$.

Traditional service learning projects can be classified as: 1) collaborations with a community group or non-profit organization (NPO) to provide specific engineering design or construction around a specific need, or 2) an internship-like experience with industry in which students provide requested work for a client. That is, in traditional SL approaches, students are assigned projects, which are commissioned by the supporting organization. Typically, traditional SL projects involve structured fieldwork in real physical locations. More recently, these types of projects have also been completed at a distance, or 'virtually' by students, through the use of the internet and software (see first row of Table I). Although such SL projects enjoy the benefits listed above, the clear limitation of both of these traditional approaches is that they do not prepare students to implement projects in industry that are not prescribed (i.e. where the identification of the project or problem is determined by the student). In contrast, this paper presents the findings for a novel pedagogical approach, which allows for self-directed SL (see the second row of Table I). Specifically, this inquiry represents a hybrid approach, in which students (a) create open-source energy conservation measure (ECM) calculators to improve the environmental and economic performance of organizations in general, and then (b) recruit specific organizations and act as change agents by providing audits and recommendations for unsolicited appropriate ECMs. Consequently, the projects contained a hybridization of virtual and real engineering service learning. For the virtual SL component, students created products that are openly available on the web, whilst for the real SL portion, students engaged in field work with organizations. These projects were not commissioned or solicited by organizations; rather, students chose which ECMs to develop, the method to develop them, and the organizations in which to study them (i.e. self-directed SL). Examples of such SL projects were integrated into a $4^{\text {th }}$-year mechanical engineering elective called 'Engineering for Sustainable Development'. These projects focused on ECMs related to green information technology and systems (IT/S), or initiatives (software and hardware) to address energy efficiency and environmental sustainability of information processing activities ${ }^{\text {xvii }}$. 
TABLE I

TRADITIONAL VERSUS SELF-DIRECTED SERVICE LEARNING

\begin{tabular}{c|c|c}
\hline & Real Location & Virtual Location \\
\hline Traditional SL & Field Work+Commissioned & Web/Software+Commissioned \\
\hline Self-directed SL & Field Work+ Un-commissioned & Web/Software+Un-commissioned \\
\hline
\end{tabular}

This paper is organized as follows. The background pertinent to the novel SL project is presented. Then, the structure of the project is outlined. The results are presented and discussed, and conclusions are drawn regarding the effectiveness of such projects and implications for engineering pedagogy.

\section{BACKGROUND}

Organizations are beginning to look beyond short-term economic indicators as their sole focus and instead, are beginning to focus on the so-called triple-bottom line of financial, social, and environmental outcomes ${ }^{\text {xiii }}$. All of these indicators are important, not only for the well-being of organizations, but also for civilization as a whole. It is also becoming increasingly apparent that environmental responsibility can support organizations' financial goals, particularly for energy consuming businesses ${ }^{\mathrm{xix}}$. Thus, businesses are under increasing pressure to address issues related to global sustainability, especially environmental responsibility ${ }^{\mathrm{xx}}$.

Environmentally responsible behaviors in organizations include conservation of resources, recycling, pollution prevention, and advocacy for environmental change ${ }^{\mathrm{xxi}}$. These initiatives often fall under the headings of corporate sustainability, corporate citizenship, or "corporate social responsibility". While western societies have typically focused on short-term financial profits over these environmental concerns, there is evidence to suggest that organizations are beginning to explore the benefits of environmental responsibility and long-term thinking ${ }^{\text {xii }}$, and Green IT/S in particular ${ }^{\text {xxiii }}$. As mentioned above, Green IT/S refers to software and hardware initiatives to address energy efficiency and improve the organization's ecological impact or environmental footprint. Examples of Green IT/S include initiatives such as implementing energy efficient computers and monitors, tele- or video-conferencing to reduce travel, or implementing environmental management systems. Despite environmental concerns, spending on IT/S is growing two times faster than the Gross World Product, and consuming large fractions of business' energy costs ${ }^{\mathrm{xxiv}}$, with important implications for the environment. In many cases, this results in wasted energy, poorly designed systems, or inappropriate behaviors. This lack of efficiency can lead to environmental issues such as increased electricity grid emissions and excessive thermal pollution. Although IT/S can have a substantial influence on organizations' ecological impacts, those environmental issues underlying IT/S often have no clearly defined ownership in organizations ${ }^{\mathrm{xxv}}$ and the IT/S function is often not considered by organizations in their assessment of their environmental footprints ${ }^{\text {xxvi }}$. Nevertheless, smarter IT/S use could reduce global emissions by $15 \%$ xxvii .

Given the complexities around sustainability and IT/S, in terms of accounting, implementation and technological complexity, Green IT/S research is best accomplished through a multi-disciplinary approach in which engineers assess energy technology opportunities, environmental and management information system researchers consider the potential for information systems to improve the organization's environmental footprint, and researchers 
utilize theories around organizational learning, change, and implementation to affect these


context of a $4^{\text {th }}$ year engineering course, the Green IT/S Project utilized service learning in studying and using IT/S resources to address the two business issues of financial and environmental performance.

\section{Engineering Service Learning Projects Studied}

For the course, the Green IT/S Project utilized service learning in studying and using IT/S more effectively in organizations. The Green IT/S Project was designed to be accomplished by engineering students using a combined approach of both service learning and commissioned assignment approaches ${ }^{x x i x, x x x}$. This type of project complements established engineering design programs because of the focus on students performing interdisciplinary research to find solutions to environmental problems. As described earlier, it has proven extremely motivational for students and is associated with positive learning outcomes ${ }^{x x x i, x x i i, x x i i i}$. For the projects, students were organized into groups of five, allowing audits to be performed for eight companies. The SL projects were broken down into five parts as summarized in Table II.

TABLE II

SuMMARY OF SERVICE LEARNING COMPONENTS OF GREEN IT/S PROJECT

\begin{tabular}{c|c|c|l}
\hline SL type & Agent & Pt & Description \\
\hline \multirow{2}{*}{$\begin{array}{c}\text { Virtual } \\
\text { SL }\end{array}$} & \multirow{2}{*}{ Student } & 1 & $\begin{array}{l}\text { ECMs and topic page: Open source investigation of a chosen Green IT/S } \\
\text { technology with literature review and quantification of economic and } \\
\text { environmental benefits through an ECM spreadsheet model uploaded to } \\
\text { Appropedia.org }\end{array}$ \\
\cline { 3 - 4 } & 2 & $\begin{array}{l}\text { Peer review and correction of ECMs: } \\
\text { This was enhanced by using the open source capability of Appropedia.org where } \\
\text { multiple students could view the project work, pages, attached documents and } \\
\text { leave feedback on the discussion board. }\end{array}$ \\
\hline \multirow{3}{*}{ Real SL } & Student & 3 & Selection and completion of a Green IT/S audit of a business \\
\cline { 3 - 4 } & Client & 5 & $\begin{array}{l}\text { Final recommendation reports to the business and work reports to the course } \\
\text { instructor }\end{array}$ \\
\cline { 2 - 4 } & & & Client survey and feedback \\
\hline
\end{tabular}

As can be seen in Table II, Parts 1-4 were student tasks and Part 5 was completed by a representative of the client company. Parts 1 and 2 represent virtual service learning objectives, whereas, Parts 3-5 represent service learning objectives that occurred in a physical organizational location.

In the SL projects, students developed ECMs and then acted as change agents for industry by auditing recruited organizations and recommending unsolicited ECMs to improve the organizations' environmental and economic performance. These initiatives ranged from incremental techniques (e.g., replacing laptops with more energy-efficient models) to more innovative solutions (e.g., using solar photovoltaic electricity to power data centers). Prior to student involvement, templates for the Green IT/S Projects were designed by a multi-disciplinary team made up of representatives from economics, engineering, environmental studies, and 
management information systems ${ }^{x x x i v}$. For the 'virtual' SL component, student teams chose and researched a green IT/S topic and developed an ECM spreadsheet calculator that would evaluate the economic and environmental impact of the ECM. These ECMs were then reviewed to ensure quality and accuracy, and open sourced on a wiki. For the 'real' SL component, the student teams performed basic IT/S audits of participating organizations, highlighting areas that would benefit most from recommended ECMs.

\section{Virtual Service Learning in the Green IT/S Project}

Parts 1 and 2 of the projects entailed using Appropedia.org as a repository and collaboration tool. Appropedia.org is a free wiki-based tool for collaborative solutions in such areas as sustainability, poverty reduction and international development. It can be used for SL especially geared towards applied sustainability ${ }^{\mathrm{xxv}}$. As a group collaboration tool, multiple users can contribute (as with a team) on different sections and the wiki file manager interface allows for a spreadsheet model to be uploaded with a record of changes made and work to be done for other team members. Electronic time stamps and signatures are used, providing a valuable history record of how students contributed to the work outcome for grading purposes. Lastly, a discussion page, attached to the main page, allows for peers to review the work and make comments and suggestions to improve their work. Collaborators globally could comment as well. Thus, instead of the traditional classroom where assignments and projects are generally for marks and likely unused thereafter, Appropedia enables the work to be part of a useful knowledge database ${ }^{\mathrm{xxxvi}}$ to enable any organization to improve the energy efficiency of their IT/S.

To prepare for the projects, Appropedia template pages and ECM excel spreadsheet templates were available on the main project website (http://www.appropedia.org/Mech425 GreenIT Project). On the website, students chose their project topics, updates were made, and their questions were answered. Projects were categorized and monitored by the course instructor and teaching assistants. Resources were also made available to help with background information on engineering economics and green IT/S.

After choosing a specific green IT/S technology, system, or methodology, students created a topic page where they presented a literature review on the subject, explaining the economic and environmental benefits and how they would incorporate them into an ECM Excel spreadsheet model. Conducting the background research allowed the students to better understand the topic from different perspectives (i.e., financial, technological) and provided references for assumptions and key data used in the ECM calculators. The ECMs were structured similarly to financial investments, such that the costs, savings and environmental benefits had to be evaluated and quantified. For example, using a more energy efficient printer would require an investment to purchase it, but the returns would include reduced energy used resulting in lower electricity costs and greenhouse gas emissions. Thus, in the ECM spreadsheet models, students were able to utilize simple payback, internal rate of return, and net present value as economic measures to evaluate the proposed Green IT/S Projects. Quantifiable environmental benefits were mainly due to reduced emissions (from electricity reduction) and conserved trees (by reducing paper), although other benefits were also mentioned. Students were graded on the communication (adequate description of the topic), presentation (clarity and flow), and accuracy (appropriate citations and thoroughness) of their submissions. Further, students were asked to peer review another group's work. The discussion page on the project webpage enabled this feedback, and signed time stamps assisted in tracking the submissions. Students were graded on 
the usefulness of their peer reviews and were given the opportunity to incorporate feedback from the reviews into their ECMs before grading. The ECMs created were to be used by various groups for Parts 3 and 4, which meant that the work had to be correct and understandable for all other students. In addition, since the ECMs were to be made available worldwide in the public domain, students were held to a higher standard than may be used in traditional course assignments. In total, thirteen ECMs were developed and approved for use by the eight student teams.

\section{Field ('Real') Service Learning in the Green IT/S Project}

Parts 3 and 4 entailed SL objectives at a physical location where student teams undertook green IT/S audits at participating companies of various kinds; both public and private (field work). As a precursor to this, students had to identify a company that would be interested in this work and obtain the appropriate consents from company representatives. The volunteering companies tended to have a vision to increase environmentally-responsible behaviors in general, but faced challenges implementing their visions. Students performed green IT/S audits at the participating company facilities, focusing on the IT/S resources, but also considering other ECMs applicable to the company. Students were required to use at least two of the thirteen available ECM models created by the class or the research team.

Once at the organizational sites, students performed audits. They used surveys, conducted interviews, collated appliance specifications, and used electricity and solar resource measuring equipment to obtain the data required for inputs to potential ECMs and to improve assumptions and default values in the ECMs. They also collected important information regarding the company's current and proposed sustainability goals, current initiatives and past implementations and sustainability program information. All data were collected with signed consent from company representatives.

The final stage of the project for the students involved the preparation of two reports: a recommendation report for the company and a work report for the course instructor. The recommendation report detailed the recommended ECMs with economic and environmental justifications for each ECM. Students also indicated implementation considerations and potential behavioral changes required for certain initiatives. All assumptions and limitations were addressed and summarized calculations were presented. The work report provided a brief overview of the company and its green initiatives, all measurements made and data collected by the students (including surveys), why the specific ECMs were chosen, and an assessment as to whether the company was a good candidate for future work. A reflection on whether learning objectives were met and the overall project experience were also included.

Following completion of the students' work, a client survey was distributed by the course teaching assistant to each participating company. Clients were asked to comment on the professionalism of the students, general evaluation of the recommendations made (including limitations and improvements), and their desire to continue participation in the green IT/S research.

\section{Outcomes of the Green IT/S Projects}

Both virtual and real service field SL components of the Green IT/S Project were successful from both implementation and education perspectives. 
Virtual Service Learning Work

Appropedia.org provided an effective platform for collaboration, allowing students to contribute useful tools for society and providing records of student contributions. In particular, students were able to produce a working advanced spreadsheet and Appropedia.org topic page, and demonstrated evidence of collaboration and peer review via history of student pages. The virtual SL enabled the topic pages and ECMs to be publicly accessible to anyone with the need. Because the students' work contributed to an on-line knowledge base, unlike traditional assignments, there seemed to be a greater sense of responsibility and commitment to their work that motivated most teams to exceed expectations. Table III shows the number of views each of the various pages received during the four month period of the course. Given that individual groups made between 50 and 150 edits, the number of views shows that these pages and the associated ECMs were accessed by many more individuals than just the immediate project team. These projects are thus clearly viewed more than traditional projects (which would generally be viewed only by individuals associated with the course and a partner organization). It is also interesting to note that the pages viewed more tended to be the projects most popular with clients due to ease of implementation and novelty.

\section{TABLE III}

Summary of Views of Green IT/S Project pages on Appropedia at end of Semester of Course (May 14, 2010)

\begin{tabular}{lc}
\hline Appropedia Page Name & Number of Views \\
\hline Main Course Green IT page & 2832 \\
Collaborating Documents Electronically & 522 \\
$\begin{array}{l}\text { Energy Monitoring } \\
\text { Energy-efficient PC/workstations } \quad(3\end{array}$ & 1044 \\
$\begin{array}{l}\text { ECMs) } \\
\text { Linear Fluorescent Retrofit (Upgrading }\end{array}$ & 751 \\
to T8 from T12) & \\
$\begin{array}{l}\text { Motion sensor controlled vending } \\
\text { machines }\end{array}$ & 923 \\
$\begin{array}{l}\text { Phantom power reducing power bars } \\
\text { Server Virtualization }\end{array}$ & 1039 \\
Telecommuting & 681 \\
\hline
\end{tabular}

Although some students naturally contribute more than others, a common problem in group work is the occurrence of 'free-riders' who obtain, with little cost or effort, the benefit of grades earned by industrious members of the group. This challenge was addressed in a number of ways. The time stamp and signature features and the ability to see the page edit history in Appropedia were a means of monitoring the level of contribution of each student. These features were highlighted for the students in order to actively discourage free-riders. Because students were aware of this monitoring, there was evidence of reasonable contribution from all group members. Figure 1 shows a screen shot of the edit history of a page on Appropedia where two versions can be compared and the frequency and authorship of edits can be found. Figure 2 shows an example of a comparison chosen. 


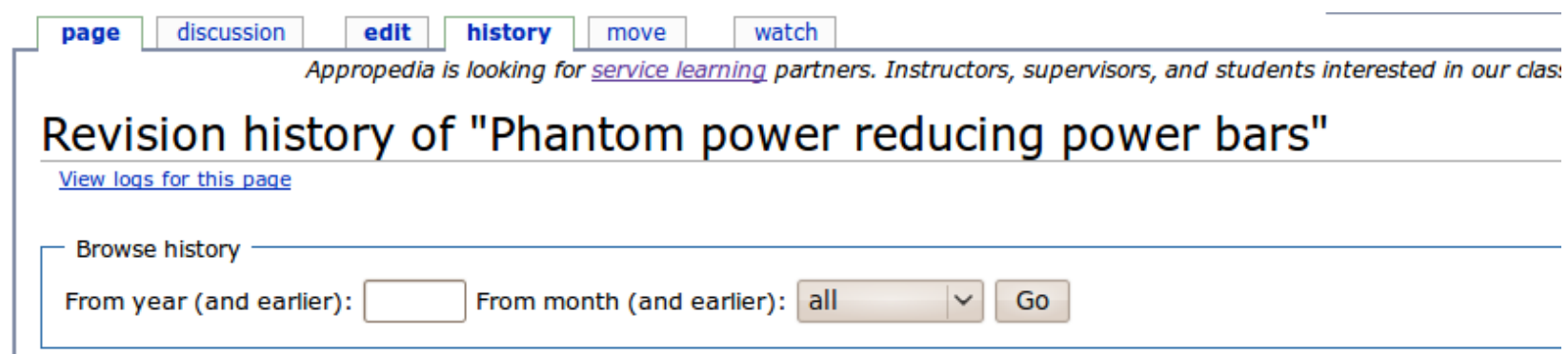

(Latest | Earliest) View (newer 500) (older 500) ( $\underline{20}|\underline{50}| \underline{100}|\underline{250}| \underline{500})$

The following are previous versions of Phantom power reducing power bars.

To see the difference between two versions, check their radio buttons and click Compare selected versions.

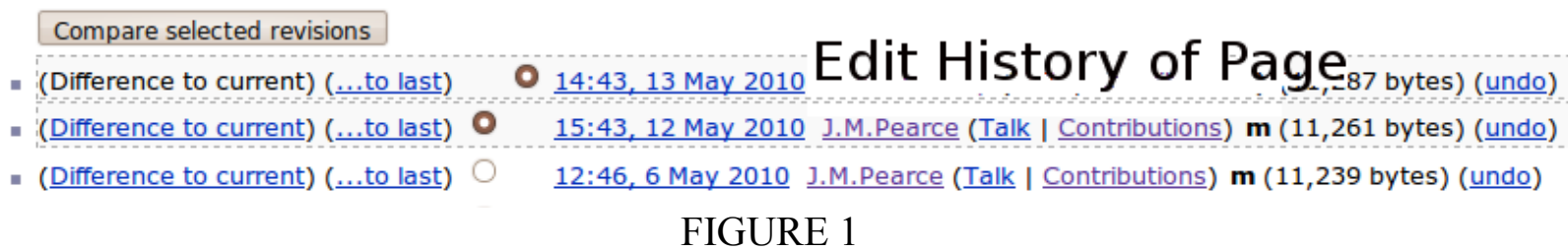

TOOL TO ENABLE COMPARING EDIT HISTORY OF PAGES

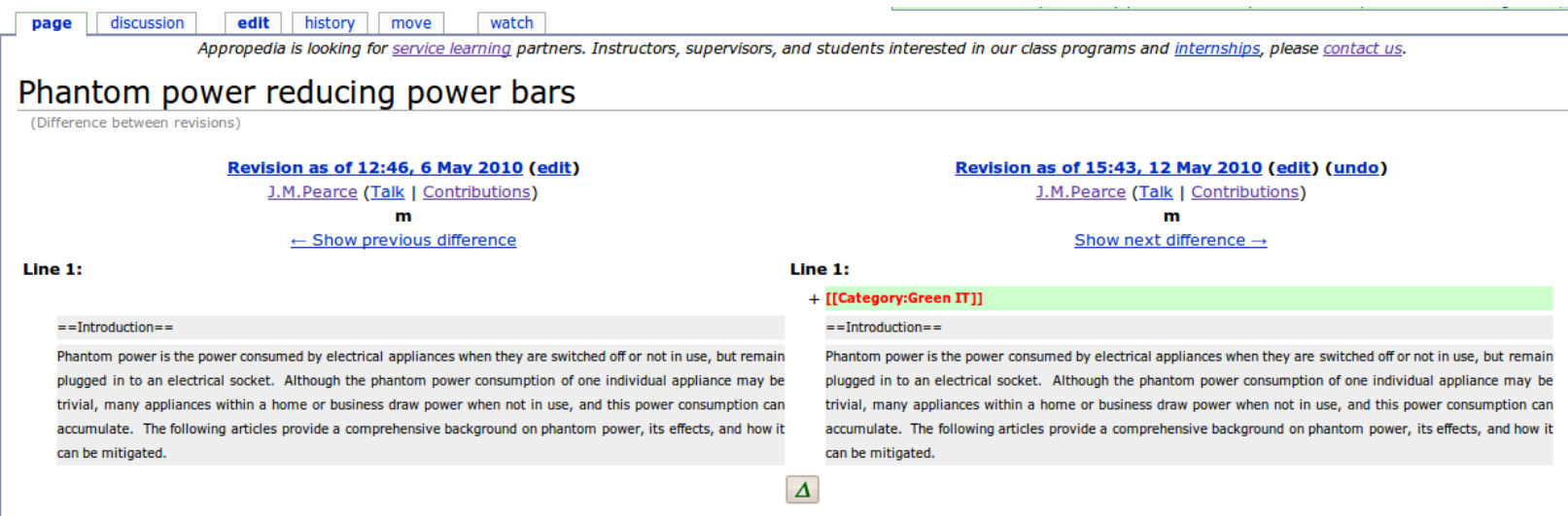

FIGURE 2

COMPARING TWO VERSIONS OF A PAGE USING THE EDIT HISTORY OF A PAGE

With most team members actively engaged in the projects, there was an opportunity for peer-to-peer learning. One area where this was most apparent was with respect to the students' expertise using spreadsheets. As students worked to create comprehensive and transparent ECM calculators, course instructors and teaching assistants observed them improving their spreadsheet skills. The open source nature of the ECMs uploaded to Appropedia meant that students could view each other's work and adopt best practices. Higher-level skills, like the use of conditional sorting, macros and drop-down lists, which were originally used by some groups, were later adopted by others. Figure 3 demonstrates a drop-down list feature used in one ECM calculator that enables the user to choose between options. Again, because the calculators were transparent, the user could add additional items to the option repository for the drop-down list as needed. Figure 4 illustrates the 'Executive Summary' page in one of the ECMs with a well-defined 
layout. Figure 5 shows how equations and citations were made apparent so that users could understand the underlying methodology of the calculations.

\begin{tabular}{|c|c|c|c|c|c|c|}
\hline 4 & A & $B$ & C & D & $E$ & $\mathrm{~F}$ \\
\hline \multicolumn{7}{|l|}{22} \\
\hline 23 & User Style (drop down list) & \multicolumn{3}{|c|}{ Usage Factor } & & \\
\hline 24 & At Full Load & & $100 \%$ & {$[\%]$} & & \\
\hline 25 & & & & & & \\
\hline 26 & & & & & & \\
\hline 27 & \multicolumn{6}{|l|}{ Directions } \\
\hline 28 & \multirow{3}{*}{\multicolumn{6}{|c|}{$\begin{array}{l}\text { Please select from the drop down list (click in cell A21) a new power supply. A co } \\
\text { list of the power supplies is available on the Assumptions \& References page. }\end{array}$}} \\
\hline 29 & & & & & & \\
\hline 30 & & & & & & \\
\hline 31 & Power Supply (drop down list) & & Efficiency & Price & Power Rating [W] & $80+$ Rating \\
\hline 32 & Sea Sonic: S12II-380B & & $85.40 \%$ & $\$ 51.99$ & 380 & Bronze \\
\hline 33 & FSP Group: FSP300-60GLS & 수 & \multirow{6}{*}{\multicolumn{4}{|c|}{$\begin{array}{l}\text { selected meets the power requirements of } y \\
\text { upply with a large enough power rating pleas } \\
\text { efficieny }\end{array}$}} \\
\hline 34 & $\begin{array}{l}\text { Sea Sonic: S1211-38Ub } \\
\text { Sea Sonic: SS-300ET }\end{array}$ & & & & & \\
\hline 35 & Sea Sonic: S5-350ES & & & & & \\
\hline 36 & Sea Sonic: SS-350ET & & & & & \\
\hline 37 & Sparke Power: SPI2501UH & & & & & \\
\hline 38 & Thermaltake:W0315RU TP & $\checkmark$ & & & & \\
\hline
\end{tabular}

FIGURE 3

EXHIBIT OF HIGHER-LEVEL SPREADSHEET FUNCTIONS - DROP DOWN LIST ENABLES USERS TO CHOOSE BETWEEN VARIOUS OPTIONS

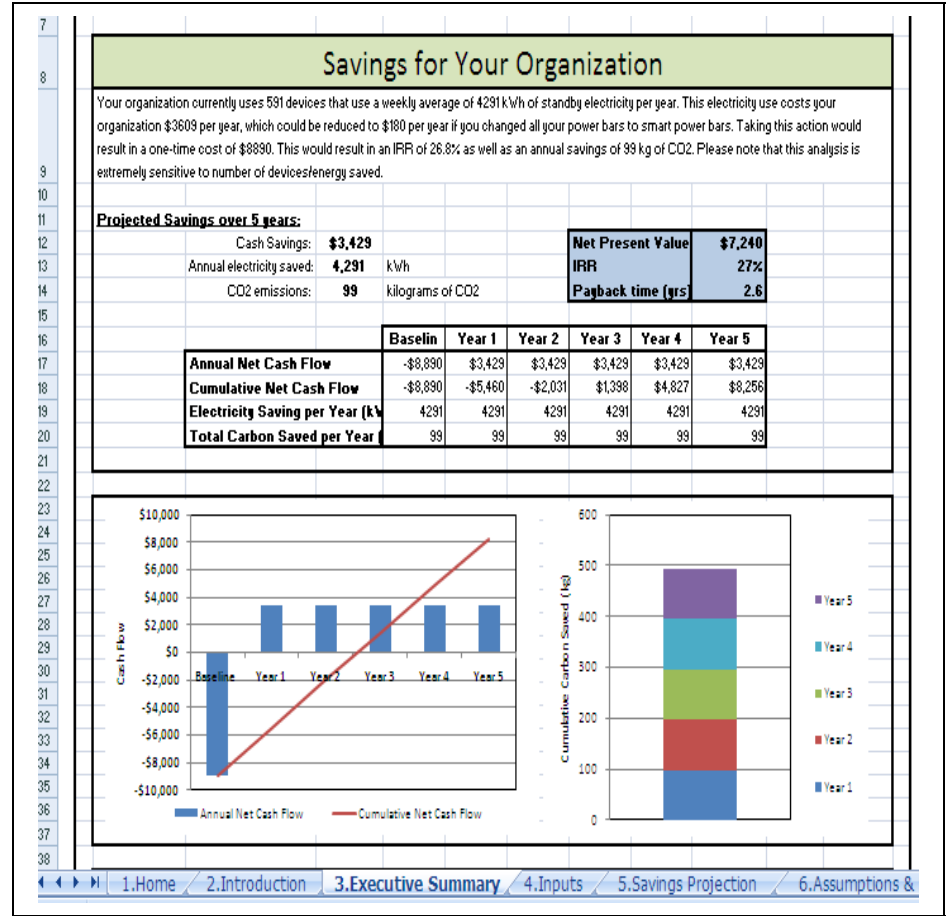

FIGURE 4

Layout of a Portion of an ECM Executive Summary Page summarizing the results of the ECM calculations. The TABS INDICATE THE DIFFERENT PAGES IN THE ECM CALCULATOR. 


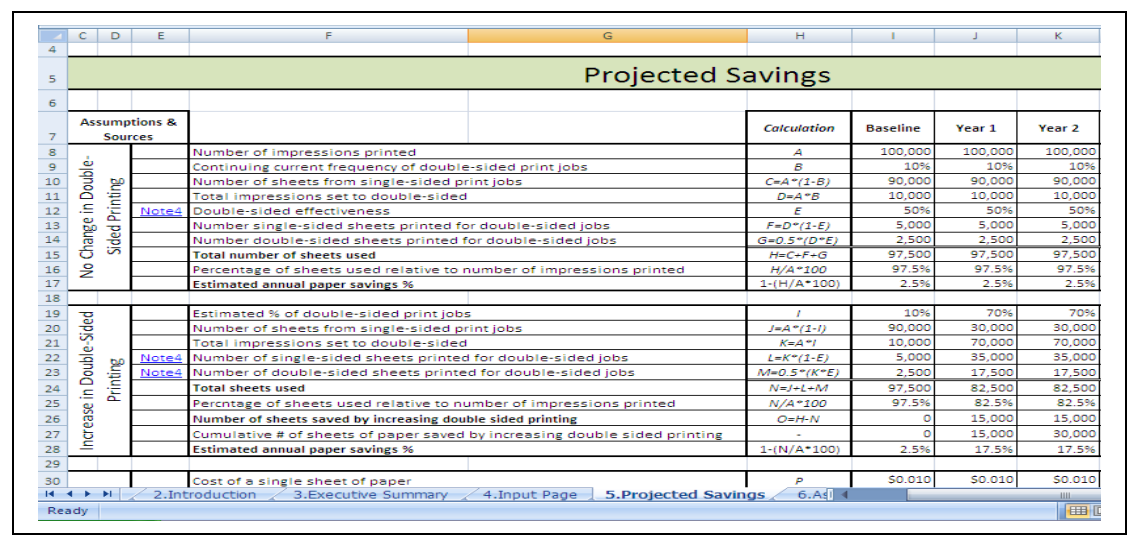

FIGURE 5

Layout of a portion of an ECM Project Savings Page Showing the citations and formulas used in the ECM

CALCULATIONS.

\section{Field or 'Real' Service Learning Work}

Eight companies participated in the field work (the number dictated by the number of teams). Companies, both private and public, of various sizes (market capitalization), from single branches to multiple branches (local, regional and/or international), represented various industry sectors, including services, technology (engineering), manufacturing, telecommunications, hotel hospitality and public service. Company experience with green initiatives also varied.

Overall reflections on the project suggest that the field SL method motivated students to demonstrate high commitment, with some students going beyond course expectations. This was evident in student feedback and demonstrated by students completing more work than required for the course objectives. Only one group used the minimum two ECMs for the field work, while the other seven teams recommended three or more to their client organizations. Many groups performed additional calculations in order to recommend initiatives tailored to their organization. One group went as far as conducting the analysis using all thirteen ECMs before evaluating which created the greatest impact for the company in terms of energy consumption reduction. Students commented that their project work felt like a real industry job and that they believed they were actually contributing to being change agents.

All participating companies remarked that the project was a good initiative and valued the recommendations of student teams, which represented an outside academic source. With the exception of one financially constrained client, all companies offered to participate in future studies. With most companies based in a city with a community sustainability plan, there seemed to be heightened interest to meet sustainability goals. Companies with regional and international operations (half of the companies) indicated that they would consider piloting the recommendations locally before expanding to their entire organization, as proper evaluations and protocol must be followed. The major limitations of the study were time and resources. Since there were only thirteen ECMS developed, the range of available initiatives was limited. Further, since the focus was on green IT/S, most applications were in service industries and within specific departments in these organizations. Thus, as one company indicated, green IT/S alone would not meet its aggressive energy reduction target. Finally, the client organizations stated that they would prefer a longer period of time spent on conducting the audit plus a follow- 
up with a future study. In this case, the academic semester structure of the course was a constraint. Table IV summarizes some of the general feedback from the clients.

\section{TABLE IV}

Summary of Common Client Feedback

\begin{tabular}{lcc}
\hline Client Statement & Number ${ }^{*} \dagger$ & Percentage \\
\hline Professional & 7 & $100 \%$ \\
Liked the project & 7 & $100 \%$ \\
Would continue the work & 7 & $100 \%$ \\
Wanted a follow up presentation & 3 & $43 \%$ \\
Foresee cost as an issue to implementation & 3 & $43 \%$ \\
Foresee technical difficulty in implementation & 3 & $43 \%$ \\
Students should spend more time on site & 1 & $14 \%$ \\
$\quad$ Recommendations not sufficient to meet company & 1 & $14 \%$ \\
\hline
\end{tabular}

*One client did not complete the survey.

$\dagger$ The sample size is not large enough for statistical analysis.

\section{Discussion}

The results recording from conducting the projects can be used to draw useful benefits and lessons for further improvement of the hybrid service learning concept.

\section{ECM Development - Virtual Service Learning Work}

In general, developing realistic ECM calculators is a non-trivial task ${ }^{\mathrm{xxxvii}}$. However, the open source platform of Appropedia enabled rapid notification of edits and corrections that needed to be made. Although general templates were created, there was still considerable freedom for student innovation in developing ECMs. Some technical difficulties were encountered during the course, such as the use of different versions of the spreadsheet software that tended to corrupt some of the files. This was managed by assessing and correcting the flaws in the file and using a more robust file upload interface that could be linked to Appropedia. In the future, it is recommended that a standard open source data processor be used such as those available in Open Office ${ }^{\mathrm{xxxviii}}$. As this was an initial attempt at constructing ECMs, significant learning occurred and the resulting development provided a ledger of improvements that can be applied to provide better templates and ECMs in the future.

This Project enabled a useful application of the basics of engineering economics, not just from a business point of view in project evaluation, but also as a tool in sustainability. Although basic engineering economics is covered in another fourth-year engineering course, many students lacked an understanding of fundamental concepts and calculations and were unsure of how to apply them in real-world projects. This was an initial hurdle to developing the ECMs. Another difficulty from an engineering perspective was determining realistic assumptions for business inputs, such as utility pricing, which differ by commercial size, labor costs, inflation estimates, risk free rate of return, capital cost allowance, financial leveraging considerations and others. 
Students were encouraged to improve ECMs used in the audits through interviews with the clients to ensure assumptions were appropriate. Overall, this project forced students out of their comfort zone in engineering to think about what motivates businesses and what sorts of presentations and discussion would be needed to promote their chosen ECMs.

\section{Field Service Learning Work}

Students developed several useful skills and learned important procedural protocols through their participation in the field work. This project was designed to provide students with the opportunity to add a vital skill set and knowledge base to their present degrees. The audits strengthened their basic understanding of energy, electricity, and applied sustainability. As well, students learned to work with rate equations, basic life-cycle analysis, cost benefit analysis, and managerial economics. The lessons can be broadly classified into ethics, business interactions, and technical and safety issues, three areas generally not taught in the classroom.

In addition to ensuring proper citations for references in their work, ethical lessons included navigating social science-based research practices such as acquiring permissions from the clients for conducting the work and collecting data, ensuring client confidentiality, and preparing value-added reports to clients in a professional manner.

In terms of business interactions, securing an appropriate client proved to be a challenge for some student teams and highlighted the importance of industry experience, networking and communication. This is different from other SL projects on campus that find clients for the students. In addition, in dealing with the companies, students gained an understanding of company protocol in terms of internal turnaround time needed for acquiring permissions, sustainability programs, visitor procedures and business organizational structures. Interviews taught students what considerations are important to a business for choosing viable projects, including the concept of using debt financing to improve the return on an investment. In general, students gained an understanding of how they would need to communicate and promote their green initiatives from technological, environmental and financial viewpoints.

Students were astonished by the level of sustainable initiatives already being undertaken by some companies. They were also surprised by what drove the implementation of green initiatives in a number of organizations: three of the clients indicated that financial metrics were not the main motivation for implementation, but rather, environmental benefits drove initiatives.

Companies voluntarily participated in the study to enhance their sustainability goals and to help overcome current roadblocks with green implementations. As mentioned previously, there was a range of companies in terms of industry sector, market capitalization and experience with green initiatives. Companies with multiple facilities could scale up benefits so that they would be more beneficial. Moreover, companies with larger IT/S or device use, such as those in the services and hospitality industries, benefited more from the green IT/S initiatives developed. Thus, students gained a realistic view of corporate social responsibility with regards to the environment.

Students acted as change agents to improve the environmental and economic performance of companies. The company selection process provided some insights into the challenges of implementing ECM initiatives. For example, students found that companies leasing offices often had no control over their energy use (utilities were included in the rent). This is a hurdle since green IT/S projects present both an economic and environmental impact. From an economic standpoint, investing in technology to reduce environmental footprints through the ECMs requires some sort of return. However, if the utilities are included in the rent, a company 
cannot offset the initial financial investment: the cost of energy would not change if the landlord did not choose to share the savings. Realizing this drawback, one company indicated that it was considering renegotiating its leases or finding new offices where they could separately control their utility bills. Another company declined participation in the Project as their management anticipated that the initiatives would not have any financial impact because the energy bills were unavailable to them. This is a lesson of paramount importance to sustainability initiatives and indicates the need for information transparency and a more direct connection between what energy companies use and who is responsible for payment.

Finally, the technical learning objectives achieved during the Green IT/S Project included using equipment to do basic energy audits, using engineering economics for a real project, and applying conventional measurement skills with proper data acquisition methodologies. The importance of safety was emphasized for the field work, and students were required to complete Workplace Hazardous Materials Information System training as mandated by the Occupation Safety and Health Act. Furthermore, off-campus risk assessment forms were completed that demonstrate student willingness to participate and knowledge of the risks of doing the audit. This experience will also be applicable to true field work in industry.

\section{Reflections on Traditional and Hybrid Service Learning}

Although traditional service learning may incorporate field and/or virtual work, the hybrid SL project presented in this paper extended previous approaches by involving an un-commissioned/ self-directed project. Unlike traditional SL, students approached companies with opportunities to improve their environmental performance through green IT/S and identified and developed the problem and solution details around efficient IT/S management. Students needed to effectively market the work they could accomplish for the companies, an additional challenge as compared with traditional SL. Although participating companies generally wanted to reduce their energy consumption, most had not considered green IT/S projects previously; thus, students presented new solutions for these organizations. Another benefit of the project was the student initiative to find volunteer companies, without arranging for organizational engagements before the term began. These actions further support companies' willingness to improve their environmental footprints, despite many challenges in doing so.

\section{Conclusions}

This paper presents the findings for a novel pedagogical exercise in which students conducted service learning projects that required them to act as change agents for industry by developing and recommending green information technology and systems energy conservation measures. Unlike traditional service learning, both self-directed virtual and field components were included. The preliminary results of this study indicate that the use of an open source tool like Appropedia.org for virtual service learning combined with a field-work-based SL component can be an effective means of achieving the dual goals of education and organizational change directed towards environmental sustainability. Future work is needed to quantify the impact on learning and the effectiveness of such an approach to catalyzing environmentally-beneficial changes in organizations.

\section{Acknowledgments}


The authors would like to acknowledge K. Sayili and I. Zelenika-Zovko for their work on the development of the ECM templates and A. Nosrat and the Appropedia Foundation for technical assistance regarding Appropedia.org. Further thanks go to the companies and students who participated in this study (confidentiality respected). This work was supported by a Social Sciences and Humanities Research Council Strategic Research Grant on Environmental Issues and a Queen's University Service Learning Grant. An earlier version of this work was presented at the Canadian Engineering Education Association (CEEA) 2010 Conference. 
${ }^{i}$ Campus Compact National Center for Community Colleges, "Introduction to Service Learning Toolkit", (Providence, RI: Brown University Press, 2000).

ii T. Ehrlich, "Service Learning in Higher Education: Concepts and Practices", in: Barbara Jacoby and Associates. (San Francisco, CA, Jossey-Bass, 1996).

iii L. Harrisberger, R. Heydinger, J. Seely, and M. Talburtt, "Experiential Learning in Engineering Education", American Society for Engineering Education, (Washington, DC, 1976), 121.

${ }^{\text {iv }}$ A. Driscoll, B. Holland, S. Gelmon, and S. Kerrigan, "An assessment for service learning: Comprehensive case studies of impact on faculty, students, community and institution", Michigan Journal of Community Service Learning, (1996), 3, 6671.

${ }^{\vee}$ D. Riley, and A.H. Bloomgarden, "Learning and Service in Engineering and Global Development", International Journal for Service Learning in Engineering, 2, no.1, (2006), 48-59.

${ }^{v i}$ S.M. Gallini, and B.E. Moely, "Service-Learning and Engagement, Academic Challenge, and Retention", Michigan Journal of Community Service Learning, 10, no. 1,( 2003), 5-14.

vii J. Eyler, and D.E. Giles, Where's the Learning in Service Learning? (San Francisco, CA, Jossey-Bass, 1999).

${ }^{v i i i}$ C. Keen, and K. Hall, "Post-Graduation Service and Civic Outcomes for High Financial Need Students of a MultiCampus, Co-Curricular Service-Learning College Program", Journal of College and Character, 10, no.2, Article 2, (2008).

${ }^{\text {ix }}$ S.M. Gallini, and B.E. Moely, "Service-Learning and Engagement, Academic Challenge, and Retention"

${ }^{x}$ J. Eyler, and D.E. Giles, Where's the Learning in Service Learning?

${ }^{x i}$ C. Keen, and K. Hall, "Post-Graduation Service and Civic Outcomes for High Financial Need Students of a MultiCampus, Co-Curricular Service-Learning College Program"

xii J. Eyler, S. Root, and D.E. Giles, "Service Learning and the Development of Expert Citizens: Service Learning and Cognitive Science", In R. Bringle and D. Duffy (eds.) With Service in Mind, (Washington, D.C.: American Association of Higher Education, 1998).

xiii J.A. Boss, "The Effects of Community Service Work on the Moral Development of College Ethics Students", Journal of Moral Education 23, (1994), 183-198.

${ }^{x i v}$ J. Miller, "Linking Traditional and Service Learning Courses: Outcome Evaluations Utilizing Two Pedagogically Distinct Models," Michigan Journal of Community Service Learning 1, no. 1, (1994), 29-36.

${ }^{x v}$ J. Pearce, and C. Russill, "Student Inquiries into Neglected Research for A Sustainable Society: Communication and Application", Bulletin of Science, Technology and Society, 23, no.4,(2003), 311-320.

${ }^{x v i}$ J. Pearce, and C. Russill, "Interdisciplinary Environmental Education: Communicating and Applying Energy Efficiency for Sustainability", Applied Environmental Education and Communication, 4, no.1, (2005), 65-72.

${ }_{\text {xvii }}$ K. Siegler and B. Gaughan, "A Practical Approach to Green IT", Webinar: http://www.itmanagement.com/land/green-itwebinar/?tfso=2058, July 14, 2008.

xviii McWilliams, A. \& Siegel, D. "Corporate social responsibility: A theory of the firm perspective", The Academy of Management Review, 26(1), (2001).117-127.

xix J.M. Pearce, D. Denkenberger, and H. Zielonka, "Energy Conservation Measures as Investments", in Spadoni, Giacomo, editor, Energy Conservation: New Research, (Nova Science Publishers: New York, 2009), 67-85.

${ }^{x x}$ H.C. de Bettignies, "Developing leadership and responsibility: No alternative for business schools" In P. H. Dembinski, C. Lager, A. Cornford, and J.-M. Bonvin (eds.), Enron and World Finance: A Case Study in Ethics, (Palgrave, Macmillan: 2006), 217-225.

xxi S. Russell, "Getting to the heart of environmental issues". Paper presented at the annual Academy of Management Meeting, (Philadelphia, PA. 2007).

xxii I. E. Berger, P. H. Cunningham, and M. E. Drumwright, "Mainstreaming corporate social responsibility: Developing markets for virtue". California Management Review, 49, no.4, (2007), 132-160.

xxiii Turner, V., Bigliani, R., \& Ingle, C. "Reducing Greenhouse Gases through Intense Use of Information and Communication Technology: Part 1”, IDC White Paper \#IDCWP31R, (2009), retrieved July 11, 2010 from http://www.idc.com/research/greenit.jsp.

${ }^{\text {xxiv }}$ K. Siegler and B. Gaughan, "A Practical Approach to Green IT"

xxv K. Siegler and B. Gaughan, "A Practical Approach to Green IT"

${ }_{\text {xxvi }}$ A.H. Huang, "A Model for Environmentally Sustainable Information Systems Development", Pacific Asia Conference on Information Systems (PACIS), Suzhou, China, 2008.

xxvii The Climate Group, "SMART 2020: Enabling the Low Carbon Economy in the Information Age". The Global Sustainability Initiative, Brussels, Belgium, 2008.

xxviii Jenkin, T., Webster, J., \& McShane, L. “An agenda for 'Green' Information Technology and Systems Research, Information and Organization”, (2010), in press. 
${ }^{\text {xxix }}$ J. Pearce, \& C. Russill, "Student Inquiries into Neglected Research for A Sustainable Society: Communication and Application"

${ }^{\mathrm{xxx}}$ J.M. Pearce, L. Grafman, T. Colledge, and R. Legg, "Leveraging Information Technology, Social Entrepreneurship and Global Collaboration for Just Sustainable Development", Proceedings of the 12th Annual National Collegiate Inventors and Innovators Alliance Conference, (2008), 201-210.

${ }^{x x x i}$ A. Driscoll, B. Holland, S. Gelmon, and S. Kerrigan, "An assessment for service learning: Comprehensive case studies of impact on faculty, students, community and institution"

xxxii J. Pearce, and C. Russill, "Interdisciplinary Environmental Education: Communicating and Applying Energy Efficiency for Sustainability"

xxxiii R.G. Bringle and J.A. Hatcher, "Implementing service learning in higher education", Journal of Higher Education, 67, (1996), 67-73.

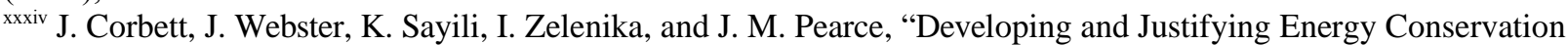

Measures: Green IT under Construction”, Proceedings of the $16^{\text {th }}$ Americas Conference on Information Systems (AMCIS), Lima, Peru, August 12-15, 2010.

${ }^{\mathrm{xxx}}$ J.M. Pearce, “Appropedia as a Tool for Service Learning in Sustainable Development, Journal of Education for Sustainable Development, 3, no.1, (2009), 45-53.

xxxvi J.M. Pearce, "Appropedia as a Tool for Service Learning in Sustainable Development”

xxxvii J. Corbett, J. Webster, K. Sayili, I. Zelenika-Zovko, and J. M. Pearce, "Developing and Justifying Energy Conservation Measures: Green IT under Construction"

xxxviii Open Office http://www.openoffice.org/ 